\title{
ChargeCar Community Conversions: Practical, Electric Commuter Vehicles Now!
}

\author{
H. Ben Brown, Illah Nourbakhsh, Chris Bartley, Jennifer Cross, Paul Dille, Josh Schapiro, Alex Styler \\ Robotics Institute \\ Carnegie Mellon University \\ Pittsburgh, Pennsylvania 15213
}

\begin{abstract}
The technology for practical, short-range electric commuter vehicles (EVs) is here now! The ChargeCar project at Carnegie Mellon University aims to exploit today's technology to make efficient, clean, quiet, commuter electric vehicles available to the public, while providing a basis for local economic development and increasing public awareness of EVs. We have developed a "kit" of modular components that can be used to convert a conventional gasoline-powered car to $100 \%$ electric power in a matter of a few days, utilizing commercial-off-the-shelf (COTS) components, along with existing manufacturing facilities and automotive garages. This kit has been installed and tested in two Honda Civics, and has performed well in over $\mathbf{3 5 0 0}$ miles of driving. The prototype vehicles have a range of $40+$ miles, top speed in excess of $70 \mathrm{mph}$, and charge overnight on any 120 VAC receptacle. Present efforts are toward commercializing the manufacturing and conversion process, while continuing related research in compound energy sytems-e.g. battery plus ultracapacitor-and pursuing educational efforts with the public and local schools.
\end{abstract}

\section{INTRODUCTION}

The Community Robotics, Education and Technology Empowerment (CREATE) Lab at Carnegie Mellon University seeks to co-design new technology innovations together with outreach and engagement strategies that demonstrate and measure how diverse communities can use creative technology responsibly to catalyze positive social change. Ongoing projects include GigaPan Education [1], which uses a lowcost gigapixel imaging robot for cross-cultural learning in dozens of countries thanks to partnerships with UNESCO and National Geographic; and Robot Diaries [2], which deploys a training program together with programmable robot hardware, software and craft materials to bridge the technology fluency gender divide in middle school. The ChargeCar project [3] combines technology development for low-cost electric vehicle conversions with direct community engagement at the high school, college, professional and lifelong-learning levels. Technically, we optimize for conversion cost and labor hours using a systems-engineering approach, aiming to significantly lower the barrier to entry for independent, local garages to provide electric vehicle conversions. We are also developing energy optimization algorithms for compound power supplies to demonstrate that low-cost batteries, together with highpower-density ultracapacitors or batteries, may yield a costeffective solution to electric vehicle energy demands when combined with intelligent, predictive, energetics controls.

\section{Electric Vehicle History}

In the early 1900's, battery electric and gasoline-powered vehicles were both part of the early personal transportation ecology, although soon thereafter gasoline-powered cars became dominant due to the far greater energy density of gasoline. While backyard conversions have been part of a popular subculture for decades, these conversions typically take many months to complete, usually with lead-acid batteries, yielding very heavy vehicles with short range. The second-generation GM EV1 and Toyota Rav4-EV, produced in the late 1990's and early 2000's, demonstrated disruptive improvements in range and reliability thanks to NiMH batteries and brushless motor technology. However legislative battles in the State of California effectively killed the EV movement at that time by removing state-mandated EV manufacturing pressure. Today, we can see a significant rebirth of interest and automotive emphasis on electric vehicles, from the Nissan Leaf and Mitsubishi MiEV to the Chevrolet Volt. These recent efforts concentrate on using the best available batteries to achieve the greatest possible range, in order to compete as successfully as possible head-to-head against extant gasoline-powered cars. Ongoing research efforts are dedicated to increasing the power density - including fast charging - and energy density of thinelectrode lithium and other exotic battery systems [4].

While the proliferation of new EV models is promising, total sales of EVs in the US in 2011 amounted to less than 20,000 vehicles [5], less than $0.15 \%$ of the total of 12.7 million in vehicle sales [6]. EVs are marketed only in selected areas, and many potential buyers are unable to purchase new EVs. Further, the pro-oil politics of a decade ago is resurfacing with Congressman Mike Kelly's bill to end the $\$ 7500$ federal tax incentive for new EVs [7]. Thus, EV conversions may still play an important role in electrifying our nation's transportation system, exploiting the distributed manufacturing capabilities and availability of used gasoline-powered vehicles. This may be our only autombile option in the event of a major oil shortage.

\section{Why ELECTRIC?}

While EVs are becoming more common-place, and technologies have improved significantly over the past decades, EVs are still largely perceived as an oddity in this country, not ready for public release. The general view is that EVs have inadequate power and range, and will not be practical until they 


\begin{tabular}{|l|l|}
\hline Perception & Truth \\
\hline $\begin{array}{l}\text { Must be exact replacement for to- } \\
\text { day's cars. }\end{array}$ & $\begin{array}{l}\text { Perfect short-range commuter vehi- } \\
\text { cle with today's technology. }\end{array}$ \\
\hline $\begin{array}{l}\text { Range too short_EV won't serve } \\
\text { all transportation needs. }\end{array}$ & $\begin{array}{l}\text { Typical daily commute under 40 } \\
\text { miles (US DoT). Many EV s have } \\
\text { range over 100 miles. Not intended } \\
\text { to replace all needs. }\end{array}$ \\
\hline $\begin{array}{l}\text { Poor performance, inadequate } \\
\text { power. }\end{array}$ & $\begin{array}{l}\text { Good acceleration, highway speeds } \\
\text { (e.g. Tesla Roadster). }\end{array}$ \\
\hline Battery technology not ready. & $\begin{array}{l}\text { NiMH batteries used reliably for 10 } \\
\text { years. LiFePO4 batteries have even } \\
\text { better energy and life. }\end{array}$ \\
\hline EVs will overload the electric grid. & $\begin{array}{l}\text { EVs ideal for off-peak charging } \\
\text { and load-leveling on a Smart Grid. }\end{array}$ \\
\hline $\begin{array}{l}\text { Massive charging infrastructure } \\
\text { needed. }\end{array}$ & $\begin{array}{l}\text { Short-range EVs can charge on ex- } \\
\text { isting 120 VAC outlets. }\end{array}$ \\
\hline
\end{tabular}

TABLE I

PREVAlent MythS REGARDING ELECTRIC VEHICLES

\begin{tabular}{|l|l|}
\hline ICE Vehicle & Electric Vehicle \\
\hline $\begin{array}{l}\text { Massive engine block to } \\
\text { contain hundreds of fuel } \\
\text { explosions/second. }\end{array}$ & $\begin{array}{l}\text { Electric motor with several moving } \\
\text { parts. }\end{array}$ \\
\hline $\begin{array}{l}\text { Hundreds of precision moving } \\
\text { parts. }\end{array}$ & A battery pack. \\
\hline $\begin{array}{l}\text { Exhaust system to muffle the ex- } \\
\text { plostions, cooling systems for en- } \\
\text { gine and transmission, lubrica- } \\
\text { tion system with periodic oil/filter } \\
\text { changes, fuel system, emission- } \\
\text { control system system to mitigate } \\
\text { pollutants, ignition system, belts, } \\
\text { chains, hoses, leaks. }\end{array}$ \\
\hline
\end{tabular}

TABLE II

Gasoline vs. Electric Vehicle Comparison

have all the capabilities of internal combustion engine vehicles (ICEVs). The reality is, however, with today's technology, EVs can fill an important niche as short or medium-distance commuter vehicles. See Table I. With a typical range of 40100 miles, good acceleration and highway speed, overnight charging on $120 \mathrm{VAC}$ outlets, EVs are quiet, clean practical vehicles today. An example of the performance potential of EVs, the Tesla Roadster-admittedly very expensiveaccelerates from $0-60 \mathrm{mph}$ in 3.6 seconds and has a nominal range of 200 miles (greater than 500 miles in ideal conditions).

EVs present significant advantages over ICEVs, including greater systems simplicity, reduced fuel use and emissions, lower operating costs. Table II shows the dramatic difference in complexity of ICEVs compared to EVs. While EVs do utilize electric power from sources that may include coal, natural gas, nuclear, etc., the overall efficiency-fuel energy to mechanical energy - is on the order of $34 \%$ for EVs vs. $20 \%$ for ICEVs [8]. Operating costs for EVs are much lower-about $\$ 0.03$ vs. $\$ 0.10-0.20 /$ mile - and emissions can be controlled more effectively at a few power stations than at millions of tailpipes. Further, EVs have none of the routine service requirements of ICEVs, and no wear-sensitive parts.

\section{Community Conversions}

The goal of the ChargeCar Community Conversions project is straightforward but challenging: design a strategy for conversion of existing ICEVs into battery electric vehicles at minimal cost and labor hours, while achieving sufficient performance for use as a practical, urban commute vehicle. Using a modular configuration of COTS electric vehicle and control components, as shown in Figure 1, along with custom electronics, we estimate the ChargeCar conversion can be completed by a typical automotive garage in 2.5 man-days, including the removal of all relevant ICE components. The concepts of reuse, minimizing life-cyle costs, and local empowerment figure prominently in this goal.

\section{A. Vehicle Selection}

The first task in the Community Conversion project was the selection of a target vehicle. Using Craigslist as a sampling of the local used vehicle market in the southwestern Pennsylvania region, we found the platform most available at low cost, low gross weight and in good structural condition was the Honda Civic series. As a base for the conversion, we selected the 7th generation (2001-2005) Honda Civic sedan, which has a curb weight of 2600 pounds, seats 4-5 passengers comfortably, and is readily available at a moderate price $(\$ 4000-7000)$ with manual transmission. Manual transmission provides greater efficiency than automatic, requires no continuous pumping of hydraulic fluid, and precludes the need for engine-sensorcontrolled shifting [9] .

\section{B. Component Selection}

The original plan for the conversion was to use low-cost series-wound, brush-type DC motors and lead-acid batteries, which have been the staples of backyard conversions for decades. However, to permit effective regenerative braking (pumping energy back into the battery pack), we found the most cost-effective option was a 3-phase AC induction motor. We selected the HPGC AC-31, rated at $30 \mathrm{~kW}$ (40 HP) peak, believing this would provide adequate performance for shortrange commuting. Analysis of estimated vehicle drag forces indicated the $30 \mathrm{~kW}$ motor would provide a top speed of 80 mph on a level highway, $60 \mathrm{mph}$ on a $2.5 \%$ grade, or $33 \mathrm{mph}$ on a $10 \%$ grade. The companion Curtis controller is rated for $550 \mathrm{~A}$ at $120 \mathrm{~V}$ max. $(66 \mathrm{~kW})$. To provide a wide speed range, we retained the original Honda 5-speed transmission coupled through the existing clutch and flywheel. Because three of the four motor/transmission mounts attach directly to the transmission, only a single, custom bracket is required to support the weight of the motor-only $36 \mathrm{~kg}$ ( 80 pounds).

Although low in initial cost, lead-acid batteries have significant drawbacks: they are heavy and bulky; have limited life, typically 500 charge cycles; and tend to be messy; and require venting and continual maintenace. Lead-acid batteries must typically be distributed in multiple packs around the vehicle, complicating mounting, cabling and temperature control, and generally require suspension upgrades to handle the added weight. The newer lithium iron phosphate (LiFePO4) batteries 


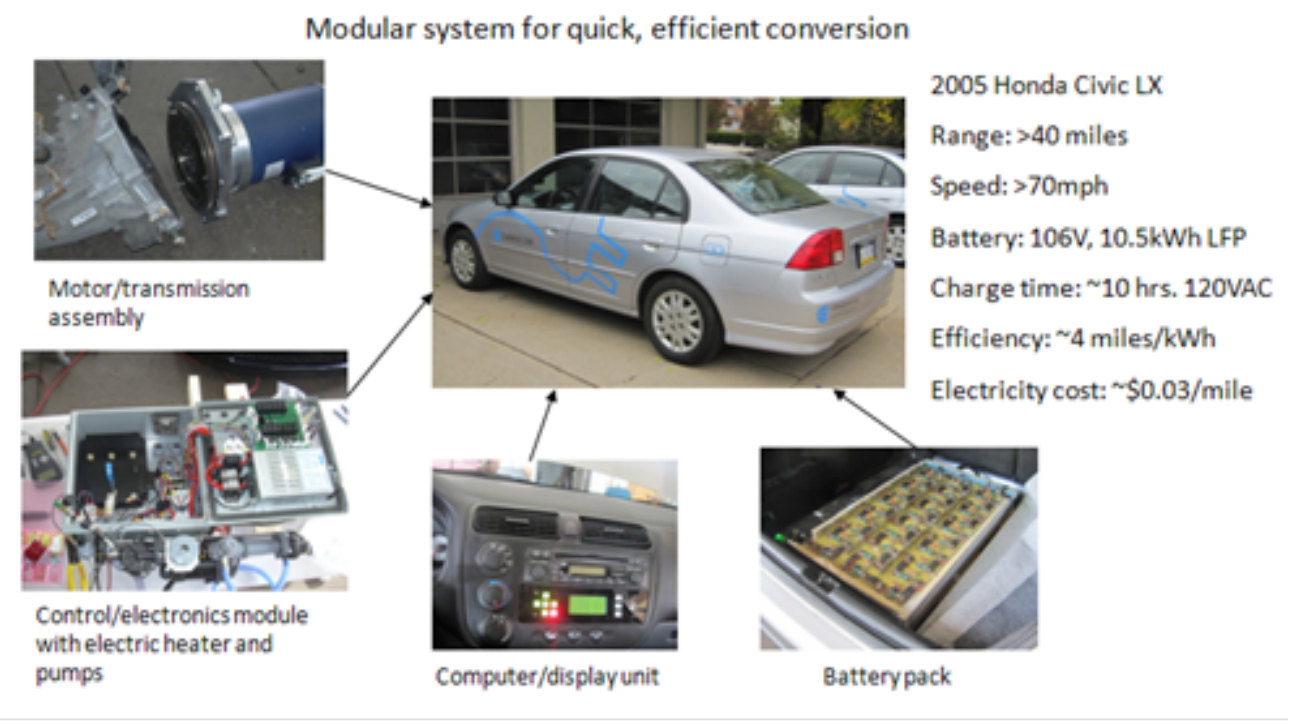

Fig. 1. Modular conversion of the Civic2

are about $1 / 3$ the weight for the same energy capacity, about $1 / 2$ the volume, are clean, and are rated for 2000-3000 charge cycles. So we opted for $\mathrm{LiFePO} 4$ cells, which, in addition to reducing weight and volume, may be less costly in the long run than lead-acid cells.

Selection of the specific lithium cells was based on desired driving range, appropriate system voltage, available space for locating the battery pack, and cost. Based on the average daily commute distance of less than 40 miles [10], we picked 40 miles as a target range per charge. At a typical 4 miles $/ \mathrm{kWh}$, this translates to a pack capacity of $10 \mathrm{kWh}$. For compatibility with the selected Curtis controller, peak voltage needed to be less than $120 \mathrm{~V}$. A 100 Ah pack at $100 \mathrm{~V}$ gives the desired $10 \mathrm{kWh}$. At $3.2 \mathrm{~V}$ per cell, a 33-cell pack gives $106 \mathrm{~V}$ nominal voltage, and $10.6 \mathrm{kWh}$, meeting the target requirements. We selected Thundersky $100 \mathrm{Ah} \mathrm{LiFePO} 4$ cells, rated for $3 \mathrm{C}(30 \mathrm{0A})$ continuous charge or discharge current, 20C (2000 A) impulse discharge. Thus the pack would be able to continuously provide the $30 \mathrm{~kW}$ of power available from the motor. The Thundersky cells (Figure 2) are less expensive than most other cells (approximately $\$ 150 /$ cell including shipping or $\$ 470 / \mathrm{kWh}$ ), and available from a number of domestic suppliers.

Qualifying the candidate Thundersky cells for this application required both unit testing to validate cell discharge characteristics in terms of Peukert efficiency [11], and thermal testing of single-cell and whole-pack configurations. Earlier EV architectures, notably second-generation GM EV1 vehicles outfitted with NiMH packs in multiple stacked layers, had suffered major life-limiting setbacks due to extreme heating of sandwiched battery layers. After conducting rapid discharge tests of individual Thundersky cell packs, we determined that at $1 \mathrm{C}$ to $3 \mathrm{C}$ discharge rates (e.g. $100 \mathrm{~A}$ for a 100 Ah battery) the batteries were still able to provide more than $90 \%$ of the

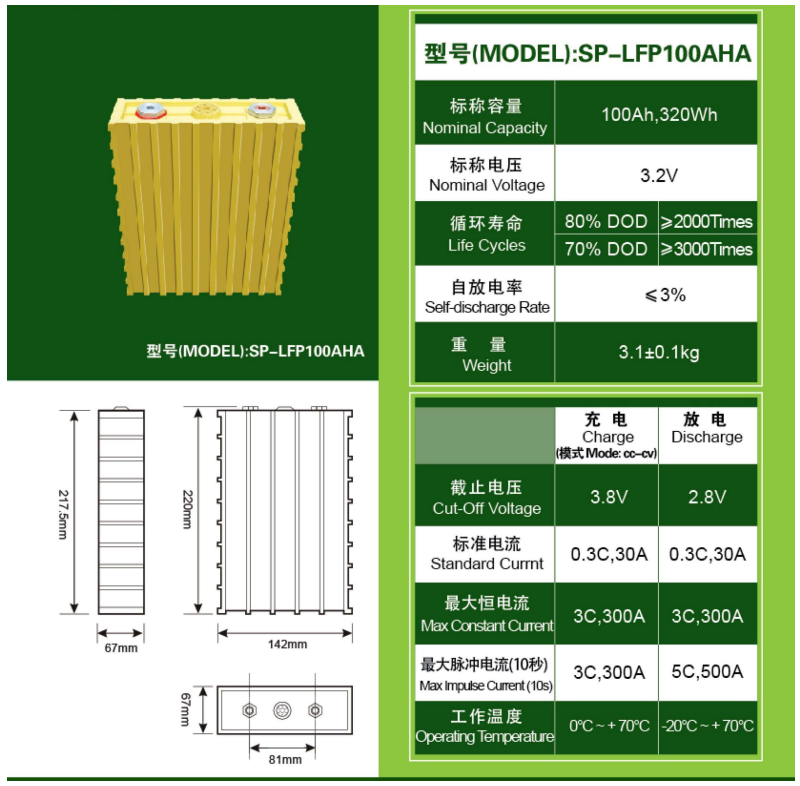

Fig. 2. Thundersky battery specifications

advertised total energy. Figure 3 shows a typical, in-vehicle plot of cell voltages. Voltage remains flat and above $3.0 \mathrm{~V}$ for $90 \%$ of the test duration. During early testing of the entire battery pack in the vehicle, we created a temporary, fully insulated battery box and drove the Civic prototype conversion with hard acceleration, plotting discharge and temperature to evaluate the need for active or passive cooling for the batteries. Surprisingly, the LiFePO4 pack stayed well below allowable thermal limits even during periods of high discharge. More recent, rigorous, full-discharge tests with similar CALB 100 Ah cells confirm that overheating of the battery pack is not a problem, even on hot summer days. 


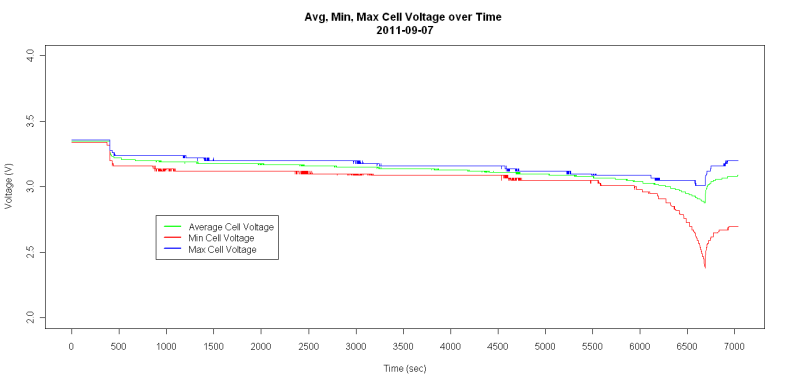

Fig. 3. Cell voltages for a typical, in-vehicle, full discharge test

The aim of our first Civic conversion was to test and verify the component selection, arrangement and vehicle performance. Our first vehicle conversion was on a 2005 Civic sedan. For simplicity, the primary electrical componentscontroller, DC-DC converter, relays, etc.- - were mounted to an aluminum plate located in the space vacated by the radiator. A crude battery box was fabricated from plywood and bolted into the trunk. Performance was found to be very satisfactory in urban and highway driving. Several methods of controlling regenerative braking were tried, including a force sensor on the brake pedal, and a thumb-operated slider on the shift lever. Ultimately, we settled on the neutral braking function available in the Curtis motor controller, which proportionally engages motor braking when the accelerator pedal is raised above the "neutral braking point" set at $20 \%$ of full depression. This provides an intuitive feel, similar to conventional engine braking, and largely precludes the need for mechanical braking. Based on the positive results with the first vehicle, we purchased a second Honda Civic, a 2002 sedan, and modified it to serve as our refined, "production prototype."

\section{Battery Placement}

Much effort was spent evaluating placement options for the batteries. Because the $\mathrm{AC}$ motor is much smaller than the components removed from the engine compartment, underhood placement was one option, at least for a partial pack. Other locations considered were the trunk and gasoline-tank space under the rear seat. We decided it was advantageous to have all cells in a single pack, for simplicity of battery temperature control (winter heating), wiring and battery management system (BMS). Based on these considerations, we selected a single-pack, single-layer configuration. Using a very tight-fitting enclosure, we were able to fit a $3 \times 11$ array of 100 $\mathrm{Ah}$ prismatic cells into the rectangular spare-tire well in the trunk of the Civic (Figure 4), leaving ample trunk space for typical commuting needs. The battery box itself provides the constraint to prevent swelling of the cells, without the endplates and straps typically provide with the cell assemblies. Total pack weight is about 300 pounds, which does not overload the rear suspension or drastically change weight distribution. Overall net vehicle weight gain is about 100 pounds. A commercial Elithion BMS monitors cell voltages and temperatures and keeps the cells balanced during charging.

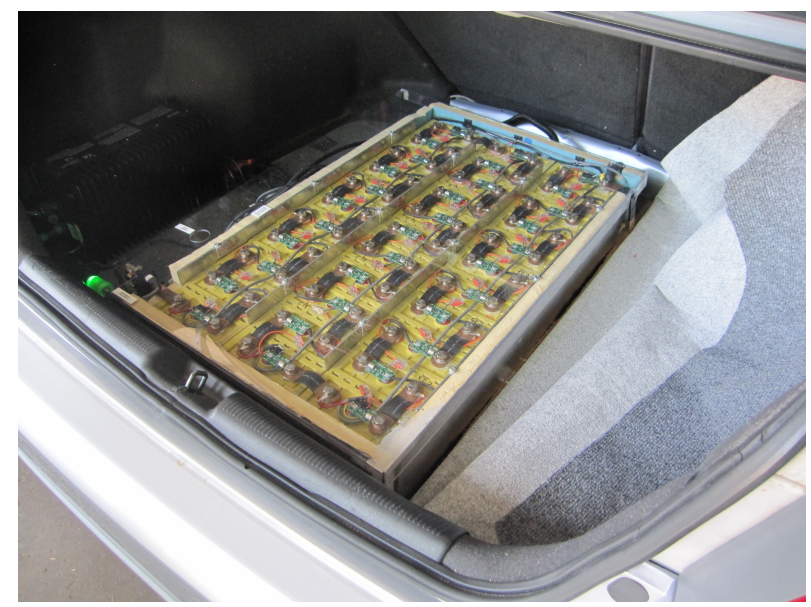

Fig. 4. Battery pack module in the trunk of the vehicle. With the pack resting in the spare-tire well, there is ample trunk space for typical commuting needs.

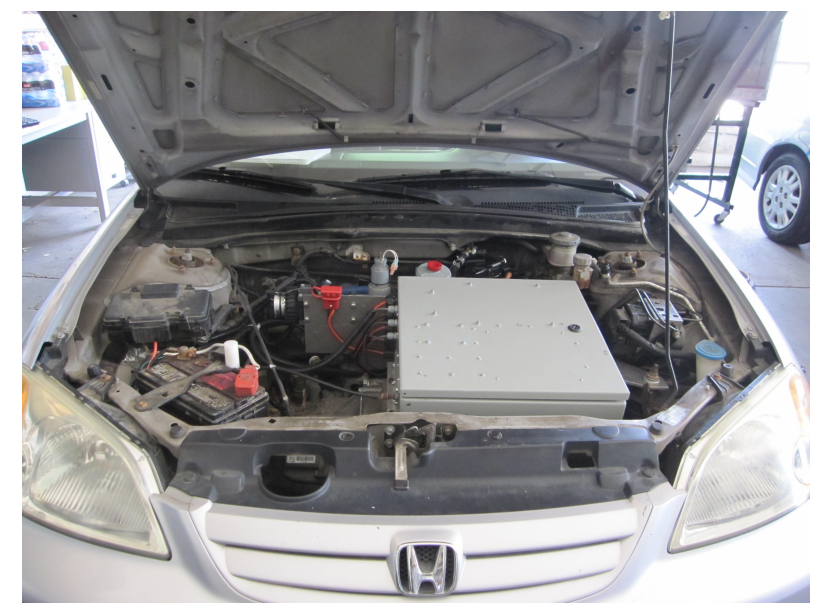

Fig. 5. Electronics box under the hood

\section{Electronics and Accessories}

The electric conversion requires a number of additional components. A 120 VAC, 12 A charger (Elcon HF/PFC 1500 W) is located with the pack in the trunk, providing a full charge of the pack in about 10 hours. To replace the original beltdriven power-steering pump, a $12 \mathrm{~V}$ electro-hydraulic pump (Toyota MR2 original equipment) is mounted under the hood along with a $12 \mathrm{~V}$ electric vacuum pump (310-VACP-K from evsource.com) that provides assist for the power brakes. For cabin heat, a custom heater module uses a $120 \mathrm{~V}$ waterheater element powered from pack voltage, or 120 VAC during charging. Strip heaters in the bottom of the battery pack, to maintain temperature above $50 \mathrm{~F}$ in cold weather, are similarly powered. A serendipitous result of our battery pack selection is the ability to use many 120 VAC components with our 106 VDC pack. The $12 \mathrm{~V}$ battery is retained to power lights, blowers, etc., and is kept charged by a DC-DC converter running off pack voltage or 120 VAC. Double-pole-doublethrow relays automatically switch to 120 VAC when the car 


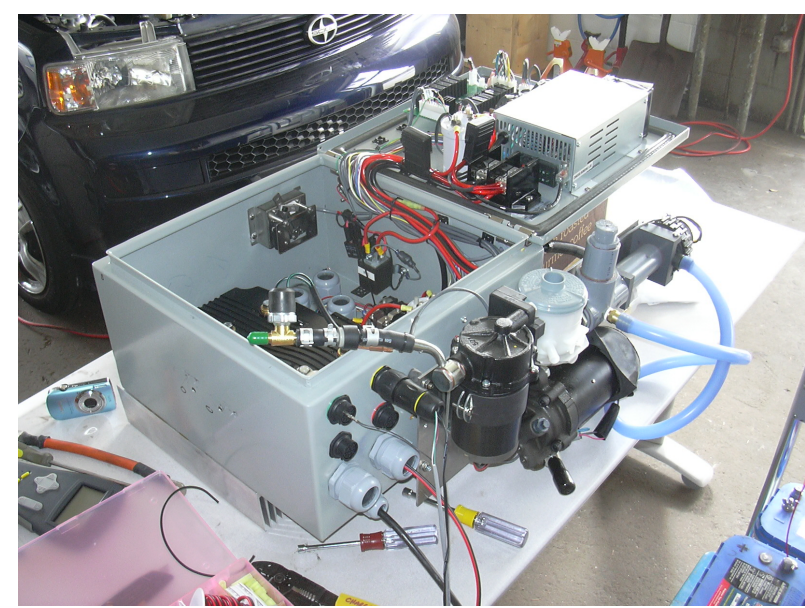

Fig. 6. The electronics box and accessories-cabin heater, pumps, reservoirs - on the bench during assembly. This all mounts as a single unit in the engine compartment.

is plugged in to charge.

For modularity and simplicity of the conversion process, all power electronics are packaged in a single NEMA4 enclosure that mounts atop the motor under the hood (Figure 5). This includes the Curtis motor controller, and circuitry and relays to operate the added pumps and heaters. Further modularity is achieved by mounting the accessory pumps and heater directly to the back of the electronics box so they are all installed as a single unit, requiring no additional mounting points. Figure 6 shows the internal components and accessories during assembly.

\section{E. Driver Display Unit}

Mounted behind the dashboard, a small computer logs all the data coming from the battery management system, a stand-alone USB GPS unit, motor and controller temperature sensors, and the original speedometer output on the transmission. The particular information displayed to the driver is selected by front-mounted buttons (Figure 7). Specific buttons on the unit also give the user control over the cabin heater and power steering, which operate on demand. The computer also interprets the motor-encoder signal (absent the original engine RPM sensor) and provides an appropriate signal to drive the existing tachometer. It actuates the brake lights when regenerative braking is in effect. All variables are recorded at $1 \mathrm{~Hz}$, and logged data can be transferred through a USB port on the front panel.

During the spring semester of 2012, a group of five students from Carnegie Mellon University's Human-Computer Interaction Institute will be working to improve the ChargeCar vehicle interface. The current interface can be difficult to see and operate while driving and has occasional reliability issues. After assessing the needs of ChargeCar drivers and the best practices of existing interfaces in commercial EV and hybrid vehicles, the students will design and build a new interface for the ChargeCar vehicles. The student team seeks to provide an interface which will enhance readability and usability, while

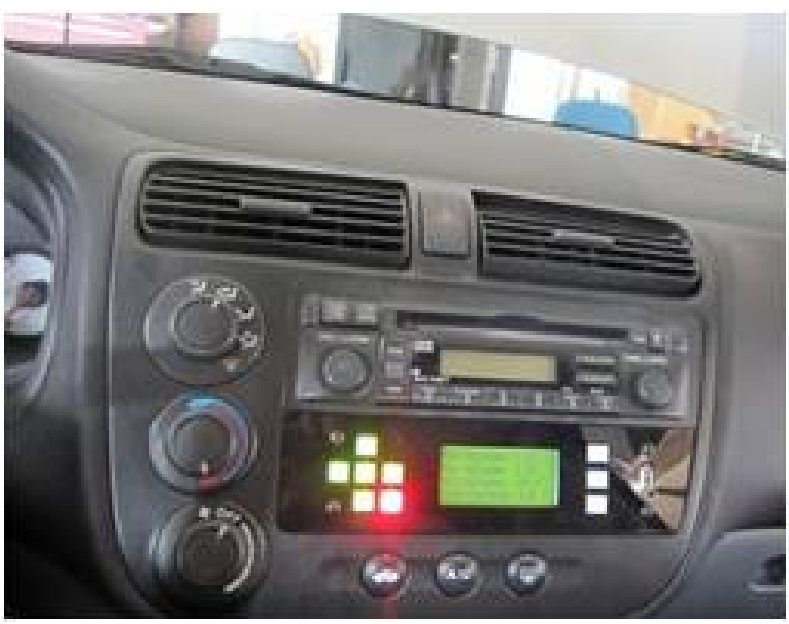

Fig. 7. The dash-mounted text display unit allows viewing of pertinent vehicle variable using button-selectable menus. A small computer logs all data at $1 \mathrm{~Hz}$ whenever the vehicle is operating.

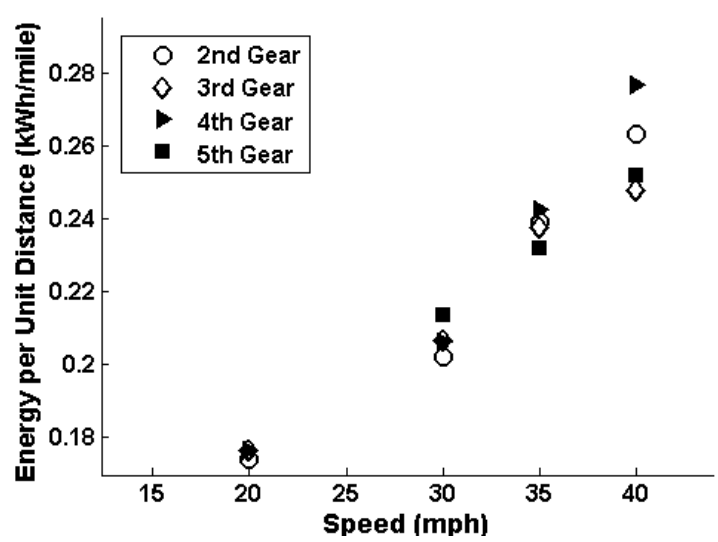

Fig. 8. Energy per mile for various speeds and transmission gear ratios. As expected, the energy requirement increases rapidly with speed, largely due to wind resistance.

minimizing the cost and changes to the existing computer and sensor infrastructure. Interfaces under consideration include a multitouch, color LCD with gesture and/or voice control, audio feedback, and an improved information layout.

\section{Vehicle Performance}

Performance of both Honda Civic EVs has been very satisfactory. We now have over 3500 miles of operation on the two Civic EVs with no major problems. The Thundersky batteries have performed well, with no signs of degradation, although early in the testing we did replace several cells in each pack that appeared to be weaker than the others (showing significantly lower voltage under load). The experimentally observed range of our Civics exceeds 45 miles under favorable conditions. Top speed of greater than $70 \mathrm{mph}$ is adequate to keep up with highway traffic, and we get acceptable acceleration from the small AC-31 motor. The performance is very adequate for urban and short-range highway driving in the hilly geographic regions surrounding Pittsburgh. Additionally, Battery bench 
tests from 1C (100 A) to 3C (300 A) have confirmed energy capacity of the Thundersky cells in use, as well as similar CALB cells. We have also designed specialized pack-discharge circuitry and programming for each $\mathrm{EV}$, enabling a $70 \mathrm{~A}$ full discharge test on the Civic2 conversion prototype, which will serve as a baseline to evaluate battery deterioration under real-world operation. Testing and experience have shown that batteries are not subject to overheating, but do need to be at or above $50 \mathrm{~F}$ for most effective power and energy output. Battery temperature is maintained by pack heaters whenever the vehicle is plugged in for charging.

We recently took Civic2 to a nearby oval racetrack to conduct controlled power tests, and are presently evaluating the data. Figure 8 is a plot of energy per unit distance at different speeds and gear ratios. The values are consistent with those obtained during normal driving, in the range of 0.18 $0.27 \mathrm{kwh} / \mathrm{mile}(5.6-3.7 \mathrm{miles} / \mathrm{kWh})$ for speeds in the range of 20-40 mph. Because of the size (curvature) limitations of the oval track, testing at higher speeds was not feasible. We plan to refine onboard instrumentation so that data logged during normal highway driving will be sufficient to give accurate efficiency measurements at higher speeds, compensating for elevation and speed variations.

\section{COMMERCIALIZATION AND OUTREACH}

The goals of the Community Conversion project are threefold. First, to develop a conversion recipe for producing EVs for community members needing practical, affordable personal transportation. Second, to increase visibility and public awareness of EVs in our region. Third, to build the economy through the manufacture, assembly and installation of conversion kits by local companies. We are now seeking a manufacturing partner who will license the technology from the university, manufacture and assemble the subsystems, and carry the process to commercial reality. A primary challenge is to keep conversion cost low enough to be economically attractive at relatively low production volumes. The cost is now above $\$ 20,000$, a large portion of which is the cost of batteries, motor and controller. Engineering refinements along with increased production volume could reduce the cost significantly. To enhance marketability, we are looking into possible subsidies including the Federal tax rebate of up to $\$ 7500$, which now applies only to new, factory-built EVs; and to state subsidies, such as the West Virginia $\$ 7500$ tax credit for "alternative fuel vehicles" which also applies to EV conversions of used vehicles [12]. There is a federal energy credit of $10 \%$ of the conversion cost, which also applies to our process.

In terms of outreach and education, the ChargeCar project aims to catalyze discussion and learning around issues of importance relating to the future of transportation. Electric vehicles are strongly linked to basic knowledge across diverse disciplines, including the national energy infrastructure; wellto-energy costs of various sources including petroleum, natural gas and renewables; systems engineering and systems analysis; human commute behavioral analysis; machine learning and

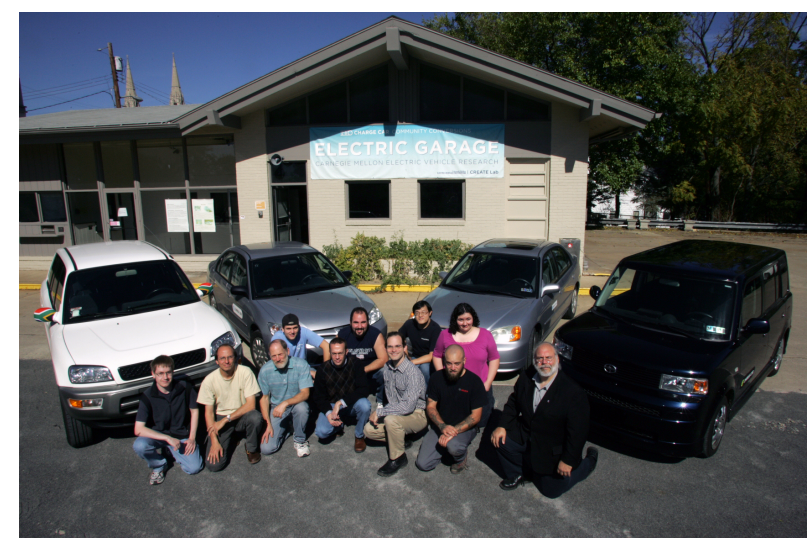

Fig. 9. The ChargeCar team in front of the Electric Garage

real-time energy management. To expose the basic science and civic politics of these issues to society, we strive to engage ChargeCar with the public in four important ways: outreach, community, ecology, and curricular co-design.

The Electric Garage facility, shown in Figure 9, is an accessible space where school groups and adult organizations can garner hands-on experience with the laboratory facilities, the conversion prototypes and this approach to local technology innovation. Garage tours frequently include incar demonstration drives in the immediate neighborhood of Carnegie Mellon University. For more sustained communitybuilding, the Electric Garage serves as a city-wide gathering place for discussions relating to transportation futures. During the summer of 2010, three types of public, community open-houses brought a range of interested parties together to learn and forge thoughts about the future of transportation in Pittsburgh. Open-houses provided a forum for other EV and renewable energy groups in Pittsburgh, to provide information to the public. Invited talks enabled guest experts to provide background information to the civic discourse, including Jay Apt, who serves on the Advisory Board of the Electric Power Research Institute. Movie screenings in the parking lot in the evenings provided a convivial way to expose the public to energy issues with outstanding documentaries, including Who Killed the Electric Car, Gasland, and Car of the Future. To further encourage public involvement, we are in the process of installing eight Eaton charging stations-obtained through a Pennsylvania Alternate Fuels Incentive Grant [13] — which will be available to the public.

\section{FUTURE WORK}

The ChargeCar conversion package requires a final systemslevel engineering analysis in order to prepare all components for small-scale manufacturing, including both mechanical and electrical hardware items such as the motor/transmission adapter plate and the wiring harnesses and connections. This task is being contracted with an outside systems-engineering firm. Following final engineering design, we hope to commercialize the conversion kit using the University's licensing process to create local centers of EV manufacturing expertise, 
potentially spreading to disparate geographic regions within the US. In tandem with this effort, we plan to broaden the suite of acceptable conversion chassis by measuring, modeling and designing conversion kits for automobiles with similar weight and body characteristics, such as the CR-V, the RAV-4 and the Corolla. In many cases, the predominant kit parts will remain the same, with changes involving couplings, hard points and enclosures.

On the educational front, our collaboration with local school systems will yield curricular units which we hope will be applicable across state boundaries together with detailed evaluations of the learning resulting from these project-based explorations of energy, transportation and systems design. We hope to disseminate these final curricular packages for broader adoption by educational institutions from early secondary to university levels.

An important future step for ChargeCar is to integrate the supercapacitor active energy management research with the Community Conversions program to enable conversions to use even less expensive traction batteries in concert with supercapacitors or high-rate batteries and an active energy management control interface. Finally, we hope to see an ecology of specific conversion recipes and approaches adopted by many garages and individuals, with an eye toward the idea that the future of transportation evolves from one of provision by a handful of companies to innovation by the masses, for the masses - a democratization of the invention process for next-generation automobiles.

\section{CONCLUSION}

The ChargeCar Community Conversions project at Carnegie Mellon University has developed a recipe for converting gasoline-powered vehicles to $100 \%$ electric power. The conversion kit is designed to be simple and modular, enabling the conversion process to be completed in a matter of a few days. The result is a practical, short-range (40-mile) commuter vehicle that has highway-speed capability, and can be charged at any 120 VAC outlet. Over 3500 miles of operation has shown the two prototype vehicles to be reliable and practical. The lithium batteries have performed according to specifications, and have shown no problem with overheating in the absence of explicit cooling, even under the most demanding conditions. The kit is designed specifically for 7th-generation Honda Civics, but should be applicable to many other vehicles with minor changes. Our current focus is on system engineering for automotive hardening, integration and simplification for manufacture, and price reduction to make the conversion more economically attractive. We are actively seeking manufacturing partners who will take the process to commercialization.

Parallel efforts are ongoing to improve range, efficiency and battery life with intelligent control. We are developing a battery/ultracapacitor compound energy system that exploits the high-power cabability of capacitors in conjunction with the energy storage of conventional batteries to improve efficiency and reduce loading on the batteries. With GPS and terrain data along with vehicle internal sensors, predictive controls can be implemented to achieve further gains.

\section{ACKNOWLEDGMENT}

The authors would like to thank Donna Auguste and David Hayes for their continuing support of this project. We also thank Bombardier, Bosch, Heinz Endowments, Intel, Google for monetary and equipment support; and Baum Blvd. Automotive and Mike's Auto Body for automotive guidance and vehicle graphics.

\section{REFERENCES}

[1] "GigaPan Conversations: Diversity and Inclusion in the Community," I. Nourbakhsh, C. Acedo, R. Sargent, C. Strebel, L. Tomokiyo, C. Belalcazar. In Proceedings of the International Scientific Conference on Technology for Development. United Nations, Lausanne, Switzerland 2010.

[2] "Robot Diaries: Broadening Participation in the Computer Science Pipeline Through Social Technical Exploration,” E. Hamner, T. Lauwers, D. Bernstein, I. Nourbakhsh, C. DiSalvo. In AAAI Spring Symposium on Using AI to Motivate Greater Participation in Computer Science, 2008.

[3] http://www.chargecar.org

[4] http://blogs.worldwatch.org/revolt/a-new-fast-charge-battery-couldjumpstart-the-electric-vehicle-market/

[5] "Why So Many Critics After 17,000 EV Sales in First Year?" Current Events, Vol 44 No. 1, January 2012

[6] http://www.foxnews.com/leisure/2012/01/04/ us-auto-sales-rose-10-percent-in-2011/U.S. "Auto Sales Rose 10 Percent in 2011," Published January 04, 2012, - Associated Press

[7] http://kelly.house.gov/press-release/202-525-0182-representative-mikekelly-introduces-bill-end-electric-vehicle-tax, "Representative Mike Kelly Introduces Bill to End Electric Vehicle Tax Subsidy," Jan 4, 2012

[8] http://truecostblog.com/2009/01/04/electric-vs-gasoline/

[9] http://www.canev.com/Faq/pages/transmissions.htm

[10] http://energy.gov/articles/energy-101-electric-vehicles

[11] http://www.gizmology.net/batteries.htm

[12] West Virginia Legislative Code, Chapter 11, Taxation; Article 6D, "Alternative Fuels Motor Vehicle Tax Credit"

[13] http://www.portal.state.pa.us/portal/server.pt/community/alternative_ fuels_incentive_grant/10492 